\title{
COMPARISON OF ANTIFUNGAL EFFECT OF XANTHORRHIZOL (CURCUMA XANTHORRHIZA ROXB.) AND 2\% CHLORHEXIDINE AGAINST CANDIDA ALBICANS AMERICAN TYPE CULTURE COLLECTION 10231 BIOFILM
}

\author{
SANNY TULIM ${ }^{1}$, KAMIZAR NAZAR $^{2 *}$, ANGGRAINI MARGONO $^{2}$, RATNA MEIDYAWATI $^{2}$, ERMI YANTI $^{1}$ \\ ${ }^{1}$ Conservative Dentistry Residency Program, Faculty of Dentistry, Universitas Indonesia, Jakarta, Indonesia. ${ }^{2}$ Department of Conservative \\ Dentistry, Faculty of Dentistry, Universitas Indonesia, Jakarta, Indonesia. Email: kamizar_kz@yahoo.com
}

Received: 30 July 2019, Revised and Accepted: 01 June 2020

ABSTRACT

Objective: Several studies suggest that $2 \%$ chlorhexidine (CHX), an effective irrigation solution against Candida albicans biofilm, is toxic to host cells, thus an effective and safe alternative irrigation solution is needed. Java turmeric (Curcuma xanthorrhiza Roxb.) containing xanthorrhizol (XNT) has been reported to have an antifungal effect, yet no studies to date have reported the optimum dose of XNT in inhibiting C. albicans biofilm, so the aim of this study was to determine the optimum dose of XNT against C. albicans biofilm.

Methods: C. albicans American Type and Culture Collection (ATCC) 10231 biofilm was exposed to XNT for 15 min. Then, the antifungal effect was tested using 3-[4,5-dimethyl-thiazol-2-yl]-2,5-diphenytetrazolium bromide reduction assay and total plate count (TPC).

Results: There was no statistically significant difference between the percentage of biofilm eradication and TPC results following exposure of C. albicans ATCC 10231 biofilm to 1\% XNT, 1.25\% XNT, and 2\% CHX.

Conclusion: Our results suggest that $1 \%$ XNT and 1.25\% XNT have an antifungal effect against C. albicans ATCC 10231 biofilm equivalent to that of $2 \%$ CHX.

Keywords: Candida albicans, Antifungal, Biofilm, Chlorhexidine, Xanthorrhizol.

(C) 2020 The Authors. Published by Innovare Academic Sciences Pvt Ltd. This is an open access article under the CC BY license (http://creativecommons. org/licenses/by/4. 0/) DOI: http://dx.doi.org/10.22159/ijap.2020.v12s2.PP-04

\section{INTRODUCTION}

Endodontic infection is not only caused by the presence of bacteria but also by fungi. The invasion of fungi can be found in primary, secondary, and persistent endodontic infections [1,2]. Siquerra et al. and Shah et al. reported that fungi have rarely be found in primary endodontic infections (prevalence: 8\%), but they seem to occur more often in persistent endodontic infections (prevalence $>18 \%$ ) [1-3]. Several species of fungi have been detected in the root canal system including, Candida, Aspergillus, Penicillium, and Fusarium species [4]. From among these species, Candida albicans is the most commonly observed species found in persistent endodontic infections [3,5]. Biofilm formation is one of the important virulence attributes of $C$. albicans because $C$. albicans cells growing in a biofilm can be 1000 -fold resistant to antifungal agents that are planktonic cells [6-8].

Several studies have shown that $2 \%$ chlorhexidine (CHX) is an effective irrigation solution against $C$. albicans $[9,10]$. Although $2 \% \mathrm{CHX}$ has been claimed to be a safe irrigation solution in endodontic treatment, Chang $e t$ al. found that $\mathrm{CHX}$ with a concentration of more than or equal to $0.0001 \%$ was toxic to periodontal ligament cells [11]. Liu et al. also observed that $2 \%$ CHX permanently halts cell migration and significantly reduced the survival of fibroblasts and osteoblasts [12]. These toxic effects can cause degeneration of the periapical tissue and delay healing [11]. Thus, further research is necessary to elucidate an effective irrigation solution against $C$. albicans biofilm without imparting toxic effects to host cells [13].

Curcuma xanthorrhiza Roxb., commonly known as Java turmeric, has been used as traditional medicinal plant in Indonesia for food and medicinal purposes. C. xanthorrhiza Roxb. contains xanthorrhizol (XNT) and curcuminoid as its active compounds [14]. XNT is the most active compound that can only be isolated from the essential oil of the rhizomes of $C$. xanthorrhiza Roxb [15]. Helen et al. reported that essential oil extracted from the rhizome of $C$. xanthorrhiza Roxb. was effective in inhibiting the growth of several fungi, including C. albicans. The dominant XNT content in essential oils used in their research indicated that XNT has an antifungal effect [13]. Meanwhile, Rukayadi et al. found that $32 \mu \mathrm{g} / \mathrm{mL}$ of XNT was able to eradicate $67.48 \%$ of C. albicans biofilm [16].

In this study, the antifungal effect of XNT against $C$. albicans American Type and Culture Collection (ATCC) 10231 biofilm was analyzed at several concentrations so that the optimum concentration of XNT against $C$. albicans biofilm might be found and its effects could be compared with those of $2 \% \mathrm{CHX}$ solution.

\section{METHODS}

\section{Culture of C. albicans}

C. albicans ATCC 10231 (obtained from the Oral Biology Laboratory cultured stock) was cultured aerobically on Sabouraud Dextrose Agar (SDA; Becton, Dickinson and Company, Franklin Lakes, NJ, USA) at $37^{\circ} \mathrm{C}$ for $48 \mathrm{~h}$. Following the incubation time period, C. albicans was collected with an ose needle until one full loop was obtained, and then inserted into a tube containing $10 \mathrm{~mL}$ of Sabouraud Dextrose Broth (SDB; Becton, Dickinson and Company, Franklin Lakes, NJ, USA) solution. The tube was centrifuged using a vortex mixer, then incubated aerobically in an incubator at $37^{\circ} \mathrm{C}$ for $48 \mathrm{~h}$ and stored at $4^{\circ} \mathrm{C}$ in the refrigerator before use. Then, C. albicans suspension was diluted to concentrations of $10^{-2}, 10^{-4}$, and $10^{-6}$. Three Eppendorf tubes labeled according to the concentration were prepared in sequence and filled with $990 \mu \mathrm{L}$ of SDB. Next, $10 \mu \mathrm{L}$ of $C$. albicans suspension was added into the Eppendorf tube labeled as $10^{-2}$ to create a $10^{-2}$ suspension and then homogenized with a vortex mixer. A $10^{-4}$ suspension was made by adding $10 \mu \mathrm{L}$ of $10^{-2}$ C. albicans suspension into an Eppendorf tube labeled $10^{-4}$ and 
homogenizing it. The same procedure continued until a $10^{-6} \mathrm{C}$. albicans suspension was obtained. Then, $C$. albicans suspension from each concentration was cultured on SDA at $37^{\circ} \mathrm{C}$ for $48 \mathrm{~h}$. According to the number of $C$. albicans colonies that could be counted visually, the $10^{-6}$ concentration of $C$. albicans suspension was used further in this study.

\section{C. albicans biofilms formation}

The formation of $C$. albicans biofilm was conducted by adding $100 \mu \mathrm{L}$ of $10^{-6}$ (containing $1 \times 10^{6}$ cells $/ \mathrm{mL}$ ) of C. albicans suspension into flatbottom 96-well microtiter plates (IWAKI; Asahi Glass Co., Ltd., Japan), according to the well design. Then, $100 \mu \mathrm{L}$ of SDB was added into each well, as growth medium, followed by $48 \mathrm{~h}$ of incubation at $37^{\circ} \mathrm{C}$ to facilitate cell attachment and biofilm formation. After incubation, the medium was discarded and non-adherent cells were removed by washing the biofilm with sterile phosphate-buffered saline (PBS) (Oxoid; Thermo Fisher Scientific, Waltham, MA, USA) solution. At this point, C. albicans biofilm samples were ready to be exposed to herbal testing.

\section{Preparation of antifungal agent}

The XNT (obtained from PT. Tri Rahardja; Javaplant, Indonesia) was isolated from the rhizome of $C$. xanthorrhiza Roxb. XNT has a brown color with a thick consistency. The analysis of XNT content was performed using gas chromatography-mass spectrometry at the Laboratorium Kesehatan Daerah in Labkesda, Indonesia, which revealed that the XNT used in this study had a concentration of 95\%. XNT was dissolved in dimethyl sulfoxide (EMSURE; Merck, Darmstadt, Germany) to obtain $0.25 \%$ XNT, 0.5\% XNT, 0.75\% XNT, 1\% XNT, and 1.25\% XNT solutions.

\section{3-[4,5-Dimethyl-thiazol-2-yl]-2,5-diphenytetrazolium bromide (MTT) assay}

C. albicans biofilm in microplates was exposed to $100 \mu \mathrm{L}$ of XNT with different concentrations $(0.25 \%, 0.5 \%, 0.75 \%, 1 \%$, and $1.25 \%)$ to be tested. In conjunction, $2 \%$ CHX $(100 \mu \mathrm{L})$ was added into the positive control well, while $100 \mu \mathrm{L}$ of SDB was added into the negative control well (i.e., biofilm without added material for testing). In this study, the XNT solutions of varying concentrations were also included as blank samples. Next, the well plates were incubated for $15 \mathrm{~min}$ at $37^{\circ} \mathrm{C}$ and then washed once with $100 \mu \mathrm{L}$ of PBS solution.

The metabolic activity of $C$. albicans biofilm was assessed using MTT reduction assay (Sigma-Aldrich, St. Louis, MO, USA). The MTT salt was dissolved in PBS to give a final concentration of $5 \mathrm{mg} / \mathrm{mL}$. The MTT solution was kept in $15 \mathrm{~mL}$ tubes and was wrapped with aluminum foil until used. Next, $200 \mu \mathrm{L}$ of MTT solution $(5 \mathrm{mg} / \mathrm{mL})$ was added to each well and wrapped in aluminum foil before incubating for $3 \mathrm{~h}$ at $37^{\circ} \mathrm{C}$ aerobically. After incubation, $200 \mu \mathrm{L}$ of acidified isopropanol solution was added to each well to stop the reaction. The plates were shaken by an orbital shaker $(80 \mathrm{rpm})$ at room temperature for $1 \mathrm{~h}$. Finally, the solution's optical density (OD) was measure by a microplate reader at a wavelength of $570 \mathrm{~nm}$. The percentage of biofilm eradication was calculated by the following formula $[17,18]$ :

Percentage of biofilm eradication $(\%)=$

$$
\left(1-\left(\frac{\text { OD sample-OD blank sample }}{\text { OD negative control-OD blank negative control }}\right)\right) \times 100 \%
$$

The OD sample is the OD of C. albicans biofilm after exposure to material tested, the OD blank sample is the OD of material tested; the OD negative control is the OD of $C$. albicans biofilm after exposure to SDB (negative control); and the OD blank negative control is the OD of SDB (blank negative control).

\section{Total plate count (TPC)}

C. albicans biofilm in microplates was exposed to $100 \mu \mathrm{L}$ of XNT with several concentrations $(0.25 \%, 0.5 \%, 0.75 \%, 1 \%$, and $1.25 \%)$. The negative control was the $C$. albicans biofilm unexposed to any antifungal agent and the positive control was the $C$. albicans biofilm exposed to $2 \%$ CHX. Next, the well plates were incubated for $15 \mathrm{~min}$ at $37^{\circ} \mathrm{C}$ and then washed once with $100 \mu \mathrm{L}$ of PBS solution. Antifungal testing using the TPC method was done by scraping the bottom of each well (after adding $100 \mu \mathrm{L}$ of PBS) with an Eppendorf tip and $10 \mu \mathrm{L}$ suspension was taken to be cultured on SDA medium aerobically at $37^{\circ} \mathrm{C}$ for $48 \mathrm{~h}$. Following incubation, the number of colonies was visually counted and data were recorded.

\section{Statistical analysis}

Data were analyzed using one-way analysis of variance with significance set at $\mathrm{p}<0.05$. We used the Statistical Package for the Social Sciences version 22.0 software program (IBM Corp., Armonk, NY, USA).

\section{RESULTS AND DISCUSSION}

In this study, XNT isolated from the rhizome of $C$. xanthorrhiza Roxb. was tested against $C$. albicans biofilm. C. albicans is by far the fungal species most commonly isolated from infected root canal with periradicular disease due to the failure of root canal treatment [1]. C. albicans is eukaryotic microorganisms that can take part in endodontic infections and thereby may participate in the etiology and pathogenesis of periradicular disease. They possess virulence attributes, including adaptability to a variety of environmental conditions, adhesion to a variety of surfaces, the production of hydrolytic enzymes, morphologic transition, and evasion of the host defense. Moreover, C. albicans biofilm is 1000 fold resistant to host defenses and antifungal agents, leading to more difficulty in treating persistent endodontic infection due to the presence of $C$. albicans $[7,8,19]$. Therefore, in this study, antifungal testing was performed on $C$. albicans biofilm with the aim of that the results can be useful to increase the success rate in endodontic treatment, especially of persistent endodontic infection.

Recently, interest in natural antifungal compounds has been increasing. Natural compounds have been proven to have better compatibility with biological systems and less side effects [14]. Some essential oils have been shown to possess antifungal properties. However, the specific active agent in the essential oils has not been identified and it is possible that minor components of the essential oils may exhibit toxic or adverse effects in vivo. XNT, an essential oil compound derived from the rhizome of Java turmeric ( $C$. xanthorrhiza Roxb.), could be a strong candidate for eliminating C. albicans biofilm [6]. XNT is a bisabolane-type sequesterpenoid compound proven to possess antifungal activity.

The C. albicans biofilm ATCC 10231 reference strain was tested in this study because this strain has been reported as commonly found in the oral cavity. Incubation at $37^{\circ} \mathrm{C}$ can support C. albicans growth and formation of pathogenic hyphae. A $48 \mathrm{~h}$ incubation period was chosen in this research because it is the optimum time for $C$. albicans to form biofilm [20].

In our research, various concentrations of XNT were exposed to C. albicans biofilm for $15 \mathrm{~min}$, referring to the previous research conducted by Sena et al. In their study, 2\% CHX solution eliminated all biofilms of various microorganisms within $15 \mathrm{~min}$, one of which was C. albicans biofilm [21]. This research is also in accordance with that conducted by Shubham et al., who found that papaya extract solution had an effective antifungal effect on $C$. albicans after $15 \mathrm{~min}$ of exposure [22].

In this study, antifungal test results for C. albicans biofilm were observed by MTT assay and TPC. The antifungal effectivities of various concentrations of XNT solution were compared with that of 2\% CHX solution as a positive control. The absorbance value (OD) of the MTT assay test was converted into a formula to calculate the percentage of biofilm eradication.

Table 1 shows the percentage of biofilm eradication of XNT at different concentrations and 2\% CHX against C. albicans biofilm. Based on the median values observed, all XNT solutions used in this study achieved a percentage of eradication, with values ranging from $30 \%$ to $99 \%$. Thus, 
all XNT solutions used in this study have antifungal effects on $C$. albicans biofilm.

The difference in significance in each group was tested using the KruskalWallis test, following a normality test with Shapiro-Wilk, which showed non-normal data. The Kruskal-Wallis test results revealed $\mathrm{p}=0.002$ $(p<0.05)$. These results indicate that at least there were differences in eradication value between the two groups of six concentrations tested.

Furthermore, to elucidate the groups with different eradication abilities, a post hoc analysis with the Mann-Whitney U-test was conducted. The significance values (p-values) from the results of post hoc analysis are summarized in Table 2 .

Based on the statistical analysis in Table 2, it was found that all XNT solutions had the ability to inhibit $C$. albicans biofilm to a degree that differed depending on the concentration used. In this study, it was revealed that $1 \%$ XNT solution was able to reduce $90 \%$ or more of the viability of $C$. albicans. Meanwhile, another study found that C. xanthorrhiza extract at a concentration of $45 \%$ could only eradicate approximately $60 \%$ of $C$. albicans biofilm [23]. This is assumed to be because the $C$. xanthorrhiza extract contained other compounds besides XNT, limiting the antifungal effect on $C$. albicans biofilm. The previous research by Rukayadi et al. found that $32 \mu \mathrm{g} / \mathrm{mL}$ was able to eradicate $67.48 \%$ of $C$. albicans biofilm. This is presumably because the dilution used in that study was too small so the optimum concentration was not obtained in eradicating C. albicans biofilm [16].
Antifungal test then continued with calculating the number of colonies (TPC method) after exposure to various concentrations of XNT solution and $2 \%$ CHX against C. albicans biofilm.

The results of antifungal testing using the TPC method are shown in Table 3.

According to Table 3, there was a difference in significance among each group tested by the Kruskal-Wallis test, following a normality test with Shapiro-Wilk, which showed non-normal data. The Kruskal-Wallis test results showed $\mathrm{p}=0.001(\mathrm{p}<0.05)$. These results indicate that there were differences in total colony growth between the two groups of six concentrations tested. Post hoc analysis findings conducted with the Mann-Whitney U-test are summarized in Table 4.

Based on Table 4, it can be seen that there was no difference in the total colony growth after exposure to $2 \% \mathrm{CHX}, 1 \% \mathrm{XNT}$, and $1.25 \% \mathrm{XNT}$, which indicates that $2 \% \mathrm{CHX}, 1 \% \mathrm{XNT}$, and $1.25 \%$ XNT have equivalent antifungal effects on C. albicans ATCC 10231 biofilm.

From this research, statistical analysis (Table 2) showed that there was no significant difference in the percentage of biofilm eradication among $1 \% \mathrm{XNT}, 1.25 \% \mathrm{XNT}$, and $2 \% \mathrm{CHX}$ solutions, where the average percentages of biofilm eradication were $96.25 \%, 94 \%$, and $93 \%$, respectively. This finding is also similar to the results of TPC. Statistical analysis of the TPC results listed in Table 4 showed that there was no significant difference between 1\% XNT, $1.25 \%$ XNT,

Table 1: The median and p-values of $2 \%$ CHX and XNT solutions in eradicating C. albicans biofilm

\begin{tabular}{|c|c|c|c|c|c|}
\hline \multirow[t]{2}{*}{ Groups } & \multirow[t]{2}{*}{$\mathbf{n}$} & \multirow[t]{2}{*}{ Median value of percentage of biofilm eradication $(\%)(\min -\max )$} & \multicolumn{2}{|c|}{$95 \%$ confidence interval } & \multirow[t]{2}{*}{ p-value } \\
\hline & & & Lower bound & Upper bound & \\
\hline $2 \% \mathrm{CHX}$ & 4 & 92.5 (90-97) & 87.96 & 98.03 & 0.002 \\
\hline $0.5 \% \mathrm{XNT}$ & 4 & $45(40-50)$ & 35.81 & 54.18 & \\
\hline $0.75 \%$ XNT & 4 & $60(40-60)$ & 39.08 & 70.91 & \\
\hline $1 \% \mathrm{XNT}$ & 4 & 96 (94-99) & 92.72 & 96.22 & \\
\hline $1.25 \%$ XNT & 4 & 94.5 (90-97) & 89.31 & 98.68 & \\
\hline
\end{tabular}

Kruskal-Wallis test $(\mathrm{p}<0.05)$. CHX: Chlorhexidine, XNT: Xanthorrhizol, C. albicans: Candida albicans

Table 2: Significance value (p-value) of differences in the ability of $2 \%$ CHX and XNT solutions in eradicating C. albicans biofilm

\begin{tabular}{|c|c|c|c|c|c|}
\hline Materials testing & $0.25 \%$ XNT & $0.5 \%$ XNT & $0.75 \%$ XNT & $1 \% \mathrm{XNT}$ & $1.25 \%$ XNT \\
\hline $2 \%$ CHX & $0.02 *$ & $0.019 *$ & $0.018^{*}$ & 0.144 & 0.659 \\
\hline $0.25 \%$ XNT & & 0.343 & 0.069 & $0.02^{*}$ & $0.02^{*}$ \\
\hline $0.5 \% \mathrm{XNT}$ & & & 0.127 & $0.019 *$ & $0.019^{*}$ \\
\hline $0.75 \%$ XNT & & & & $0.018^{*}$ & $0.018^{*}$ \\
\hline $1 \% \mathrm{XNT}$ & & & & & 0.304 \\
\hline
\end{tabular}

Kruskal-Wallis test $(\mathrm{p}<0.05) .{ }^{*}$ Indicates the presence of differences in the percentage of $C$. albicans ATCC 10231 biofilm eradication between groups.

CHX: Chlorhexidine, XNT: Xanthorrhizol, C. albicans: Candida albicans

Table 3: Median and p-values of total colony growth after exposure of $2 \%$ CHX and various concentrations of XNT against $C$. albicans biofilm

\begin{tabular}{llll}
\hline Groups & $\mathbf{n}$ & Median value of total colony (Min-Max) & 95\% confidence interval \\
\cline { 3 - 4 } & & & Lower bound \\
\hline $2 \%$ CHX & 4 & 0 & Constant \\
$0.25 \%$ XNT & 4 & $6(5-6)$ & 4.95 \\
$0.5 \%$ XNT & 4 & $2(2-3)$ & 1.45 \\
$0.75 \%$ XNT & 4 & $1(0-2)$ & -0.29 \\
$1 \%$ XNT & 4 & 0 & Constant ber bound \\
$1.25 \%$ XNT & 4 & 0 & Constant \\
\hline
\end{tabular}

Kruskal-Wallis test ( $\mathrm{p}<0.05)$. CHX: Chlorhexidine, XNT: Xanthorrhizol, C. albicans: Candida albicans 
Table 4: Significance values (p-values) of total colony growth after exposure of $2 \%$ CHX and various concentrations of XNT against C. albicans biofilm

\begin{tabular}{lllll}
\hline Material testing & $\mathbf{0 . 2 5 \%}$ XNT & $\mathbf{0 . 5 \% X N T}$ & 0.75\% XNT & 1.25\% XNT \\
\hline $2 \%$ CHX & $0.011^{*}$ & $0.011^{*}$ & $0.046^{*}$ & 1 \\
$0.25 \%$ XNT & & $0.015^{*}$ & $0.017^{*}$ & $0.011^{*}$ \\
$0.5 \%$ XNT & & & $0.044^{*}$ & $0.011^{*}$ \\
$0.75 \%$ XNT & & & $0.011^{*}$ & $0.046^{*}$ \\
$1 \%$ XNT & & & & \\
\hline
\end{tabular}

Mann-Whitney U-test $(\mathrm{p}<0.05),{ }^{*}$ Indicates the presence of differences in the percentage of $C$. albicans ATCC 10231 biofilm eradication between groups.

CHX: Chlorhexidine, XNT: Xanthorrhizol, C. albicans: Candida albicans

and 2\% CHX, while no colony growth of C. albicans was observed following culture on SDA medium. Thus, it can be concluded that the antifungal effects of $1 \%$ XNT and $1.25 \%$ XNT were equivalent to that of $2 \%$ CHX. Therefore, according to the two antifungal tests we conducted, the optimal concentration of XNT against $C$. albicans biofilm was $1 \%$.

XNT is a phenol derivative compound so it is assumed to have the same antifungal mechanism as other phenol derivatives. Phenol compounds have a high penetration rate into the cell membrane through hydrogen binding between hydroxyl groups in the phenol compound and cell membrane proteins, which cause a membrane permeability imbalance. This mechanism makes the essential components (i.e., protein, DNA, and RNA) of the cell leak out and cause cell death [15,24]. This is similar to the research conducted by Rukayadi et al., who found that XNT affected the external morphology, exhibiting deformation and protrusion of the cell surfaces of $C$. albicans in examination by scanning electron microscopy [25]. Rukayadi and Hwang (2006) also examined the mechanism of action of XNT against Streptococcus mutans biofilm. From their research, it was reported that XNT was able to reduce the viability of Streptococcus mutans biofilm because XNT could kill Streptococcus mutans cells in the outer layer of the biofilm as these cells have direct contact with XNT so that the dead cells could be degraded and released from biofilm, resulting in reduced biofilm viability [26]. Henriques et al. in their study stated that the $C$. albicans biofilm structure resembles the biofilm structure of oral bacteria species. Thus, a similar antifungal mechanism is assumed to occur with XNT against $C$. albicans biofilm [27].

\section{CONCLUSION}

In this study, XNT was proven to have an antifungal effect on C. albicans ATCC 10231 biofilm. We assumed that this natural herbal may be a potential candidate for use as an irrigation solution in endodontic treatment, especially in persistent endodontic infections where C. albicans is commonly detected in addition to other bacterial species (reference). In particular, the $1 \%$ XNT and $1.25 \%$ XNT solutions in this study had antifungal effects equivalent to that of $2 \%$ CHX solution against C. albicans ATCC 10231 biofilm. Thus, the optimum concentration of XNT solution to use against C. albicans ATCC 10231 biofilm is $1 \%$. The results obtained herein can be further studied; aiming to evaluate the antifungal effect on XNT against $C$. albicans biofilm isolated from infected root canals so that the research of $\mathrm{XNT}$ as an irrigating solution in endodontic treatment can be further progressed.

\section{ACKNOWLEDGMENT}

This study was supported by the Directorate of Research and Community Engagement of Universitas Indonesia, funded by PITTA grant funds. The publication of this manuscript was supported by Universitas Indonesia.

\section{CONFLICTS OF INTEREST}

The authors have declared that there are no conflicts of interest.

\section{REFERENCES}

1. Siquerra JF, Rocas IN. Microbiology and Treatment of Endodontic Infection. In: Pathway of the Pulp. St. Louis, MO: Mosby Inc.; 2011. p. 559-600.

2. Shah N, Madhu KS, Murthy BS, Hemanth B, Mathew S, Nagaraj S. Identification of presence of Candida albicans in primary root canal infections: An in vitro study. Endodontology 2016;28:109-13.

3. Jose F, Siquerra J, Rocas IN. Persistent and Secondary Endodontic Infection. In: Treatment of Endodontic Infection. London: Quintessence Publishing; 2011. p. 122-36.

4. Ghorgre P. Endodontic mycology: A new perspective of root canal infection. Res Rev J Dent Sci 2014;2:43-50.

5. Siqueira JF Jr., Sen BH. Fungi in endodontic infections. Oral Surg Oral Med Oral Pathol Oral Radiol Endod 2004;97:632-41.

6. Yaya R, Han S, Yong D, Hwang J. In vitro activity of xanthorrhizol against Candida glabrata, C. guilliermondii, and C. parapsilosis biofilms. Med Mycol 2011;49:1-9.

7. Perumal P, Mekala S, Chaffin WL. Role for cell density in antifungal drug resistance in Candida albicans biofilms. Antimicrob Agents Chemother 2007;51:1454-63.

8. Taff HT, Mitchell KF, Andes DR. Mechanisms of Candida biofilm drug resistance. Future Microbiol 2013;8:1-17.

9. Kalyoncuoglu E, Tunc ES, Ozer S, Keskin C, Bilgin K, Birinci A. Evaluation of antifungal efficacy of QMix 2in1 as a final irrigant: An in vitro study. Niger J Clin Pract 2016;19:807-10.

10. Mohammadi Z, Asgary S. A comparative study of antifungal activity of endodontic irrigants. Iran Endod J 2015;10:144-7.

11. Chang YC, Huang FM, Tai KW, Chou MY. The effect of sodium hypochlorite and chlorhexidine on cultured human periodontal ligament cells. Oral Surg Oral Med Oral Pathol Oral Radiol Endod 2001;92:446-50.

12. Liu JX, Werner J, Kirsch T, Zuckerman JD, Virk MS. Cytotoxicity evaluation of chlorhexidine gluconate on human fibroblasts, myoblasts, and osteoblasts. J Bone Jt Infect 2018;3:165-72.

13. Mary HP, Susheela GK, Jayasree S, Nizzy AM, Rajagopal B, Jeeva. Phytochemical characterization and antimicrobial activity of Curcuma xanthorrhiza Roxb. Asian Pac J Trop Biomed 2012;2:637-40.

14. Oon SF, Nallappan M, Tee TT, Shohaimi S, Kassim NK, Saariwijaya MS, et al. Xanthorrhizol: A review of its pharmacological activities and anticancer properties. Cancer Cell Int 2015;15:1-15.

15. Lee LY, Shim JS, Rukayadi Y, Hwang JK. Antibacterial activity of xanthorrhizol isolated from Curcuma xanthorrhiza Roxb. against foodborne pathogens. J Food Prot 2008;71:1926-30.

16. Rukayadi Y, Hwang JK. In vitro activity of xanthorrhizol isolated from the rhizome of Javanese turmeric (Curcuma xanthorrhiza Roxb.) against Candida albicans biofilms. Phytother Res 2013;27:1061-6.

17. Quave CL, Plano LR, Pantuso T, Bennett BC. Effects of extracts from Italian medicinal plants on planktonic growth, biofilm formation and adherence of methicillin-resistant Staphylococcus aureus. J Ethnopharmacol 2008;118:418-28.

18. Costa GA, Rossatto FCP, Medeiros AW, Correa AP, Brandelli A, Frazzon AP, et al. Evaluation antibacterial and antibiofilm activity of the antimicrobial peptide P34 against Staphylococcus aureus and Enterococcus faecalis. Ann Braz Acad Sci 2018;90:73-84.

19. Nobile CJ, Jhonson AD. Candida albicans biofilms and human disease. Annu Rev Microbiol 2015;69:71-92.

20. Ramage G, VandeWalle K, Wickes BL, López-Ribot LJ. Characteristics of biofilm formation by Candida albicans. Rev Iberoam Micol 2001;18:163-70.

21. Sena NT, Gomes BP, Vianna ME, Berber VB, Zaia AA, Ferraz CC, et al. 
In vitro antimicrobial activity of sodium hypochlorite and chlorhexidine against selected single-species biofilms. Int Endod J 2006;39:878-85.

22. Shubham S, Samant PS, Khanal R, Gautam V, Birring OJ, Arora C, et al. Papaya extract as new endodontic irrigant. IOSR J Dent Med Sci 2018;17:23-8.

23. Puspitawati R, Maira U, Suniarti DF, Salma A. Inhibition and eradication effect of Javanese turmeric (Curcuma xanthorrhiza Roxb.) extract against mature phase biofilm of Candida albicans. Assoc Support to Oral Heal Res 2019;19:886.

24. Mangunwardoyo W, Deasywaty, Usia T. Antimicrobial and identification of active compound Curcuma xanthorrhiza Robx. Int J Basic Appl Sci 2012;12:68-78.

25. Yaya R, Hwang JK. The effect of xanthorrhizol on the morphology on Candida cells examined by scanning electron microscopy. Microbiol Indones 2007;1:98-100.

26. Rukayadi Y, Hwang JK. In vitro activity of xanthorrhizol against Streptococcus mutans biofilms. Lett Appl Microbiol 2006;42:400-4.

27. Henriques M, Azerado J, Oliveira R. Candida albicans and Candida dubliniensis: Comparison of biofilm formation in term of biomass and activity. Br J Biomed Sci 2006;63:5-11. 